\title{
Assessment of the social accountability of the faculty of medicine at University of Gezira, Sudan
}

\author{
S. Elsanousi, ${ }^{7}$ M. Elsanousi, ${ }^{2}$ O. Khalafallah ${ }^{3}$ and A. Habour ${ }^{4}$
}

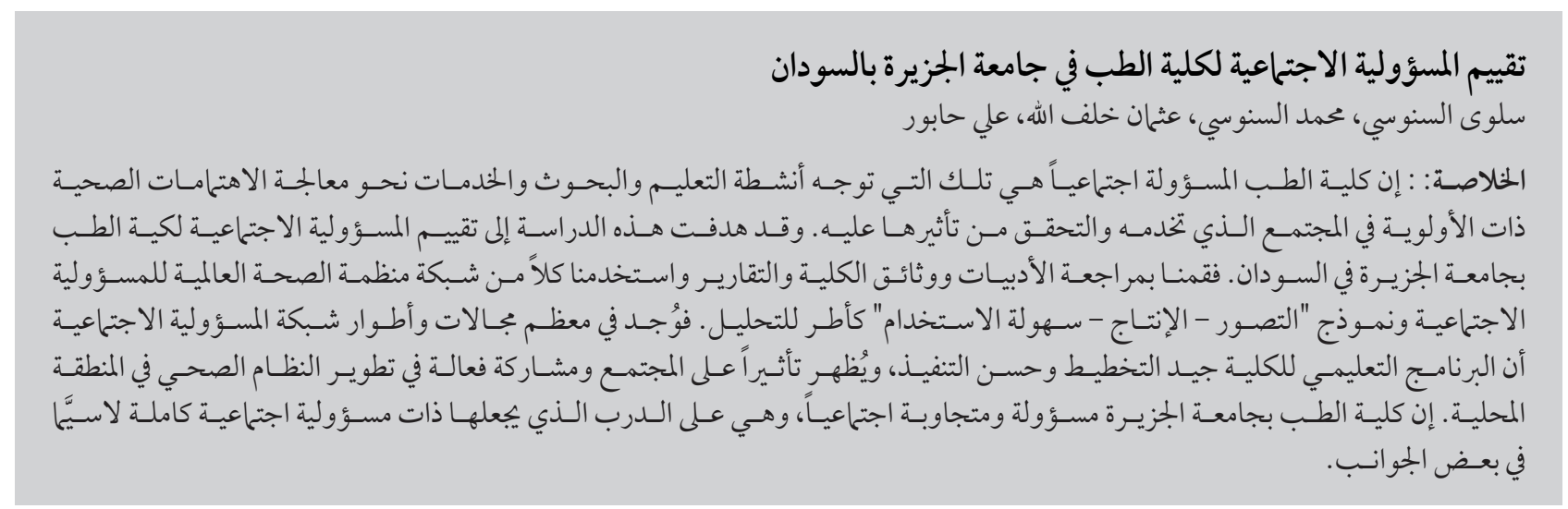

ABSTRACT A socially accountable medical school is one that directs its education, research and service activities towards addressing the priority health concerns of the community it serves and verifying its impact on the community. This study aimed to assess the social accountability of the University of Gezira faculty of medicine in Sudan. We reviewed the literature, faculty documents and reports and used both the World Health Organization social accountability grid and the conceptualization-production-usability model as frameworks for analysis. In most of the domains and phases of the social accountability grid, the faculty's educational programme was found to be well-planned and well-implemented, demonstrating an impact on the community and active participation in health-system development in the local area. The University of Gezira faculty of medicine is socially responsible and responsive and is on the way to becoming fully socially accountable in certain aspects.

\section{Évaluation de la redevabilité sociale de la Faculté de médecine de l'Université de Gezira, Soudan}

RÉSUMÉ Un établissement d'enseignement médical socialement redevable est un établissement qui oriente son enseignement, sa recherche et les activités de ses services de façon à répondre aux préoccupations sanitaires prioritaires de la communauté qu'il sert et qui vérifie l'impact que cette démarche peut avoir à cet égard. La présente étude avait pour objectif d'évaluer la redevabilité sociale de la Faculté de médecine de l'Université de Gezira au Soudan. Nous avons examiné la littérature, les documents et les rapports de la faculté, et avons utilisé la grille de responsabilité sociale de l'Organisation mondiale de la Santé ainsi que le modèle de conceptionproduction-utilisabilité comme cadres pour l'analyse. Dans la majorité des domaines et des phases de la grille de responsabilité sociale, le programme d'enseignement de la faculté s'est révélé être bien planifié et correctement mis en œuvre, et a prouvé avoir un impact sur la communauté et sa participation active au développement des systèmes de santé à l'échelle locale. La Faculté de médecine de l'Université de Gezira est responsable et réactive sur le plan social, et est sur le point d'accéder à une pleine redevabilité sociale à certains égards.

${ }^{7}$ Department of Community Medicine; ${ }^{2}$ Department of Obstetrics and Gynaecology; ${ }^{3}$ Department of Medicine; ${ }^{4}$ Department of Paediatrics, Faculty ofMedicine, University of Gezira, Medani, Sudan (Correspondence to S. Elsanousi: salwasanousi@yahoo.com).

Received: 17/03/13; accepted: 24/02/16 


\section{Introduction}

The World Health Organization (WHO) defined the concept of social accountability of medical schools in 1995 as "the obligation to direct their education, research and service activities towards addressing the priority health concerns of the community, the region, and/or the nation they have a mandate to serve. The priority health concerns are to be identified jointly by governments, health care organizations, health professionals and the public. An educational institution should verify its impact on society by following basic principles of quality, equity, relevance and effectiveness and by active participation in health system development." (1).

The global consensus on social accountability of medical schools published in 2010 was a landmark for future medical education worldwide (2). The consensus statement defines social responsibility as a state of awareness of duties to respond to society's needs and social responsiveness as a course of actions addressing society's needs. It covers 10 thematic areas that are reviewed and considered in the discussion of the findings of our study (see Box 1).

Several international networks of medical schools have prioritized social accountability of health profession schools, including the Towards Unity For Health network, which set up a task force on social accountability and institutional accreditation (4). The added value of socially accountable schools is their commitment to ensuring that their products - that is, the graduates, research findings and health care models - make an impact on the health system's performance and on people's health status, in accordance with the values of quality, equity, relevance and effectiveness (2). A solid partnership with the main stakeholders in health is a prerequisite for those schools. It is especially encouraging to see the pioneering work of a small but growing number of schools such as the Training for Health Equity network (THEnet), which are transforming their role to become active players in the development of healthier, more equitable societies (5).

Since its establishment in 1975 the University of Gezira in Gezira State, Sudan, has had a mandate to serve the Gezira community through implementation of integrated community courses across the different faculties. From its inception, the faculty of medicine adopted the principle of community-based medical education and involved health system policy-makers and community leaders at different levels (state, local administrative units, towns and villages) in the planning, implementation and evaluation of the faculty's curriculum (6). Learning in the community constitutes $25 \%$ of the curriculum and has been demonstrated in the domains of service, research and training (7).
The aim of this study was to determine whether the University of Gezira faculty of medicine is progressing towards being a fully socially accountable medical school. We did this by examining faculty curriculum documents, reports of the faculty and students and reports of visiting experts to obtain evidence that the faculty is applying the principles of social accountability. We also assessed the relevance of the findings and their conformity with some of the thematic areas for social accountability determined by the global consensus.

\section{Methods}

\section{Data sources}

This was a retrospective study based on a review of internal and external reports and a review of the faculty's documents and evaluation reports. The main sources of data were: a review of the students' and the medical school's reports of two programmes from 2001 to 2014: the interdisciplinary field training, research and rural development programme; and the family attachment programme. This covered the number of families involved, the number of visits conducted and what sort of services the students were providing. We also made a review of data from the family medicine programme from 2013 to 2014 to identify how many villages were covered, the population covered,

\section{Box 1 Thematic areas of the Global Consensus for Social Accountability of Medical Schools (3)}

Area 1: anticipating society's health needs

Area 2: partnering with the health system and other stakeholders

Area 3: adapting to the evolving roles of doctors and other health professionals

Area 4: fostering outcome-based education

Area 5: creating responsive and responsible governance of the medical school

Area 6: refining the scope of standards for education, research and service delivery

Area 7: supporting continuous quality improvement in education, research and service delivery

Area 8: establishing mandated mechanisms for accreditation

Area 9: balancing global principle with context specificity

Area 10: defining the role of society 
the number of patient visits, the number of telemedicine consultations made by faculty staff and the impact of the programme on maternal mortality and other health indicators. We also reviewed the reports of visits by external medical education experts to the faculty of medicine.

\section{Frameworks for analysis}

Two frameworks were used to assess whether the school met the definition of social accountability. The WHO social accountability grid is a framework for assessing a medical school's progress towards social accountability in each of the three domains of institutional responsibility: education, research and service (8). The grid can be used to assess the extent to which these three domains contribute towards building a health-care system that is relevant to the needs of the community or nation and provides high-quality care that is cost-effective and equitable. During the evaluation process, progressive phases in each of the cells of the grid are indicated under three headings: planning, doing and impacting. The other framework we used was the conceptual model, which measures three interdependent domains concerning health personnel: conceptualization, production and usability (9). Conceptualization involves the collaborative design of the kind of professional needed and the system that will utilize his or her skills. Production concerns the main components of training and learning. Usability concerns initiatives taken by the institution to ensure that its trained professionals are put to their best use.

We summarized the evidence from the reports under the headings of the WHO social accountability grid's domains and phases. In each domain the evidence for application of each value was summarized under the headings: planning, doing and impacting. The findings were written in each cell of the grid, and summarized according to each domain. The evidence from the conceptual model domains were addressed and summarized accordingly.

\section{Results}

\section{Applying the social accountability grid}

Applying the WHO social accountability grid (Table 1) revealed that there were two main areas that needed to be addressed in the faculty's progress towards social accountability: the costeffectiveness of the research domain and planning for quality services.

\section{Education domain}

The University of Gezira's curriculum is based on the integration of social and biomedical sciences in a holistic approach to health and well-being that takes account of the socioeconomic determinants of health. Throughout their education, students are exposed to a variety of leaning and training opportunities in which priority health concerns in the community are addressed. This is stated in the mission of the medical faculty. The medical school participates actively in outbreaks of any genuine community health problem by providing the community with the necessary prevention and control measures through community courses at family and community levels. Hence it conforms to thematic area 1 of the global consensus for social accountability (Box 1). The faculty is committed to evaluating the relevance of its educational programme to the needs of the community via an evaluation of its impact on health of the community which is done every 10 years (7).

One of the most important strategies that demonstrate the relevance aspect (Table 1) of the faculty is its partnership with the local health service providers and community-related sectors. This partnership has been strengthened by political commitment from the Gezira State government. The state government established the state coordination council, which is headed by the governor, with the members drawn from the deans of the faculties and their counterparts in the ministers of related sectors. The objective of this council is to strengthen coordination between the different sectors. This facilitates the training of medical students in community sites and the implementation of health developmental projects. It also provides opportunities for the different faculties to participate actively in state projects. In this aspect the medical faculty has also shown its conformity with thematic area 2 of the global consensus for social accountability (Box 1).

Our review of two programmes illustrate the relevance aspect in the education domain. The interdisciplinary field training, research and rural development programme is summarized in Box 2. Groups of 10-15 students are assigned to one village and carry out a group project, supervised by a group of staff members. The groups are responsible for the development of the village community in which they stay through the three phases of the programme. Box 3 summarizes the outcomes of the family attachment programme over the same period. The programme aims to enable students to play an active role in the delivery of primary health care at the level of the family, by providing a link between families and the nearby health centres.

\section{Services domain}

The medical faculty shares responsibility with other parts of the health system for ensuring equitable and quality healthservice delivery to the entire population of Gezira State. The Ministry of Health in collaboration with the University of Gezira established the rural visiting consultant programme in which faculty staff consultants provide outreach services by attending outpatient clinics and performing surgical operations at rural hospitals.

The education development centre is based in the faculty of medicine and is administered by the dean of the faculty. 


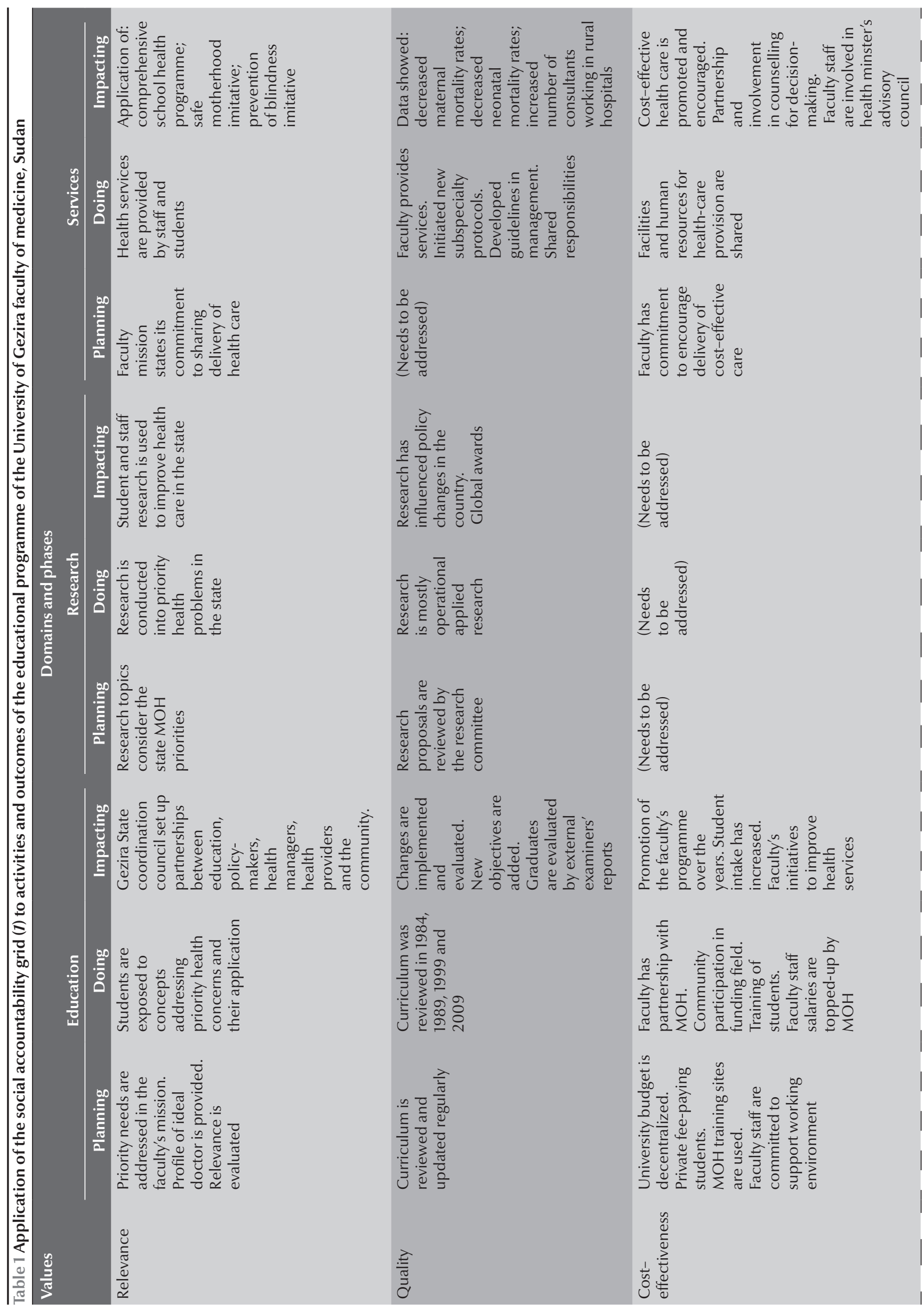




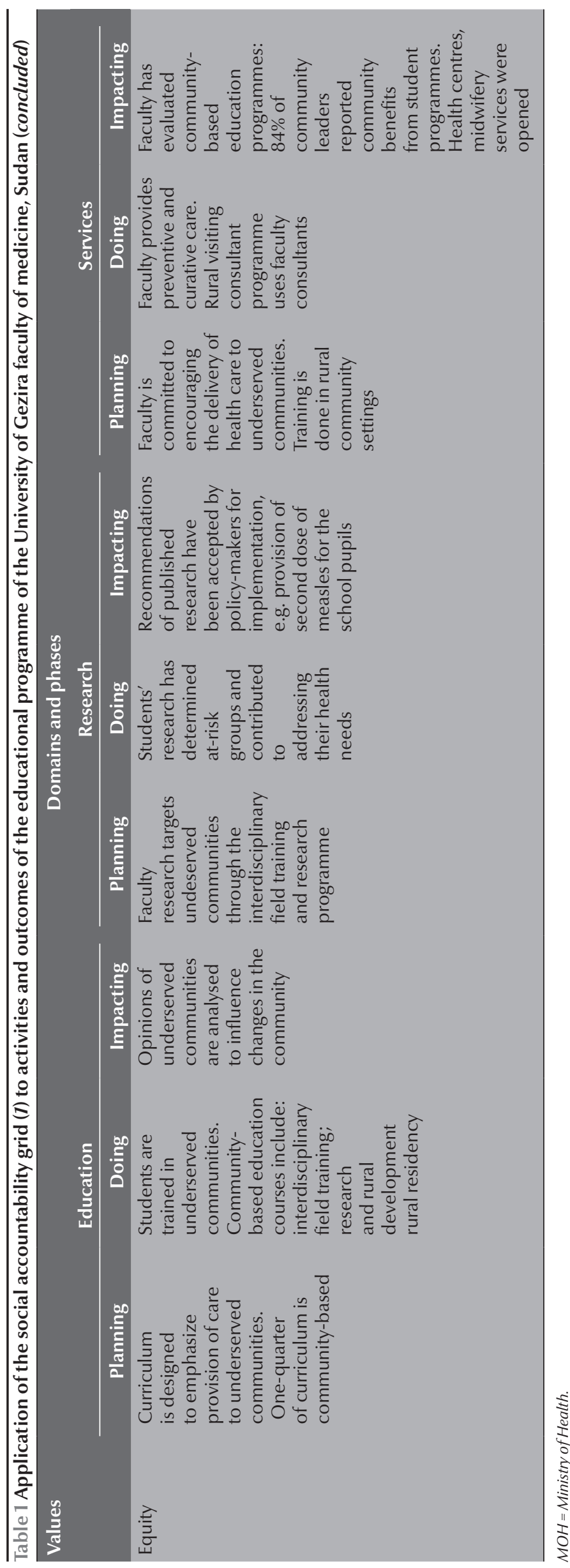

It is a collaborative centre with the WHO Regional Office for the Eastern Mediterranean Region. It has a mandate to train faculty staff and Ministry of Health medical and paramedical staff as required by $\mathrm{WHO}$. It also organizes advanced training courses for medical staff at the State and national levels. The faculty of medicine staff participate actively in the national health programmes such as malaria control, school health, expanded programme of immunization and the national AIDS programme.

The family medicine programme was initiated in Gezira State in 2010. It was designed as an in-service training model. The first enrolled batch of family medicine doctors for the Masters degree in Family Medicine at the faculty of medicine are distributed in 158 health centres in remote rural areas where they are most needed. About one-third of them are graduates of the University of Gezira. This reflects the role of the University in its surrounding communities by being the main provider of health-care personnel for the area (10). The programme is also a good example of partnership between education and health institutions (11). The Ministry of Health selects candidates, employs them, pays their salaries and meets their training fees in the faculty of medicine. As part of this programme the faculty has reduced its fees by $50 \%$. The impact of the family medicine programme on Gezira State over the 2-year period 2013-2014 is summarized in Box 4. This includes the types of consultations handled by the telemedicine system, which uses WebEx software for lectures and tutorials and ooVoo software for e-clinic consultations. The number of maternal deaths on arrival at hospital were reduced substantially after provision of the family medicine services in local health centres. The family medicine doctors manage the cases appropriately and refer them promptly before complications occur and most of the time follow them up in the ambulance until the patient arrives at the hospital.

\section{Research domain}

Research proposals from researchers at the Gezira faculty of medicine have to meet the criteria set jointly by the faculty itself, the state and the federal ministry of health. These criteria guide the researcher to address the health research priorities of the state and the country at large. This provide evidence that the faculty's research efforts influence health-care decision-makers, health professionals and consumers in an effort to improve the provision of relevant health-care services. 


\section{Box 2 Overview of the interdisciplinary field training, research and rural development programme of the University of Gezira faculty of medicine from 2000 to 2014}

The interdisciplinary field training, research and rural development programme targets 15-20 villages each year in six areas of Gezira State (8). Over the period 2000-2014 the programme covered 237 villages (82\% of the 290 targeted villages), with coverage of villages ranging from $75 \%$ to $90 \%$ in different areas. The programme has three phases each of 4 weeks. In phase 1 villages are surveyed and priority problems selected according to the community diagnosis in each village. In phase 2 students select projects and implement them in collaboration with the villagers and recruit money from the zakah chamber, nongovernmental organizations and charitable institutes and individuals. In phase 3 students evaluate their achievements.

A total of 140 projects have been completed (59\% of all projects). In all villages the following are implemented:

- health campaigns;

- tree planting;

- free mobile clinics;

- health education; and

- school health programmes.

Prominent projects are:

- directly observed therapy-short course for tuberculosis units;

- rehabilitation of water networks; and

- detection, referral and management of cases of mycetoma, schistosomiasis and vitamin A deficiency.

An example of the impact of research conducted by the University of Gezira staff on health decision-making concerns recommendations about the second dose of measles vaccine made in a published study conducted by one of the faculty staff( 12). This was discussed in a symposium held in Gezira State on World Immunization Day, and was subsequently introduced into Sudan by the federal health ministry department concerned with the expanded programme on immunization.
With regard to the quality of research, the faculty of medicine encourages applied research that will enhance quality assurance activities, such as research on evidence-based practice guidelines, medical outcomes and other areas of health delivery that directly affect the ability of practitioners to deliver quality health services. For example, the faculty has a memorandum of understanding with Norfolk and Norwich health authority in England to train paramedical staff to improve their attitudes towards infection control in Wad Medani teaching hospitals. This was expressed in the form of practical training of the nursing staff about infection control and prevention in the ward environment. Some of the postgraduate students have addressed this issue in their graduation theses.

One of the important research surveys in Sudan was carried out by University of Gezira medical faculty staff: an HIV bio-behavioural survey

\section{Box 3 Overview of the family attachment programme of the University of Gezira faculty of medicine from 2000 to 2014}

The family attachment programme is implemented among families of Gezira State in four phases during four consecutive semesters (2-4, 8). Each student makes four family visits in each phase, i.e. 16 visits by the end of the four phases. The total number of families involved during the last 15 years was 3750 and the total number of family visits conducted in the last 15 years was 50 000. The average number of students per batch is 250 . The services provided by students include:

- under-five child services, including ensuring vaccination completion according to the national expanded programme of immunization for each child, and growth monitoring at the health centre;

- linking pregnant women to the antenatal care and family planning services at health centres;

- health education according to the detected problems, addressing preventive, curative and rehabilitative measures at the household level;

- follow-up and advice for controlling noncommunicable diseases such as diabetes mellitus and hypertension;

- identification of patients in need of financial support and helping them to obtain it through the zakah chamber, health insurance and charities; and

- help in the referral of cases to secondary and tertiary levels. 


\section{Box 4 Overview of the family medicine programme of the University of Gezira faculty of medicine from 2013 to 2014}

The family medicine programme operates in 258 villages of Gezira State (total population 3575 280), with 144 health centres covered by family medicine doctors. Over the period 2103-2014 University of Gezira students made a total of 2280960 patient visits and conducted 3563 consultations via the telemedicine system. The types of medical problems handled by the telemedicine system are shown below:

$\begin{array}{lc}\text { Frequency of type of consultation of } 2 \text { years telemedicine reports 2013-2014 } \\ \text { Surgery } & 9 \% \\ \text { Ear, Nose \& Thraot } & 6 \% \\ \text { Ophthalmology } & 6 \% \\ \text { Dermatology } & 10 \% \\ \text { Obstetrics \& Gynaecology } & 13 \% \\ \text { Paediatrics } & 22 \% \\ \text { Medicine } & 34 \%\end{array}$

of female sex workers in Sudan from 2011-12 (13). The survey was conducted by staff of the department of community medicine and obtained very valuable data that helped the director of the HIV/AIDS programme in planning training packages for the HIV focal persons in the different states of Sudan and addressing the control of the disease among vulnerable groups (female sex workers and the men who have sex with men). The training was conducted at the Blue Nile Institute for Communicable Diseases. Both activities (the survey and the training) were organized by University of Gezira staff and conducted in collaboration with the director of the national HIV/AIDS programme and the United Nations Development Programme.

The proportion of the faculty's budget allocated to research related to social accountability is not strictly defined, although it may reach about $10 \%$ of the faculty's research budget. This in addition to research under the THEnet initiative which aims to conduct joint research addressing social accountability.

\section{Applying the conceptual model}

The results of applying the conceptual model in the three different domains are summarized in the following paragraphs.

\section{Usability domain}

The domain of usability involves initiatives taken by the institution to ensure that its trained professionals are put to their best use. As mentioned earlier, a good example of usability is the University's family medicine programme in which 200 doctors were enrolled and allocated to rural health settings; $32 \%$ of these are University of Gezira graduates (10). Another example of usability is that $40 \%$ of the medical faculty staff are University of Gezira graduates; these school staff are offering curative services in the teaching hospitals in Medani city where the school is located. The state health ministry has eight administration directorates, four of which are headed by University of Gezira graduates. Hence, we can conclude that the usability aspect of the model has been addressed by Gezira medical school.

\section{Conceptualization domain}

The domain of conceptualization involves the collaborative design of the kind of professional needed and the system that will utilize his or her skills. The regulations of the University of Gezira faculty enrolment system state that $50 \%$ of places in the medical school are reserved for students from underprivileged, deprived areas of Gezira State and therefore we can conclude that the school addresses the domain of conceptualization.

\section{Production domain}

The domain of production looks at the main components of training and learning and requires that the faculty aims to train the students in community settings to sensitize them to the nature of their practice in the future.

\section{Reports of visiting medical education experts}

Reports of visits by medical education experts to the faculty of medicine were included in our review.

WHO in its report stated that "the University of Gezira has changed attitudes to medical education in Sudan by pioneering a community-oriented and community-based approach that aims to improve population health outcomes. Each student is attached to a particular family for the period of their training. Student teams consult community members to identify priorities around which they develop projects and then seek funding for implementation and evaluation. Changes to the teaching programme were initially resisted by students. They even went on strike to protest that the new approach would lower the quality of their education and qualifications, turning them into medical assistants rather 
than doctors. However, as evaluations began to show a $70 \%$ reduction in maternal and child mortality in Gezira State, the model gained credibility and has now been adopted by some 30 other medical schools in the country." (11).

An external assessor appointed to evaluate the programme reported: "The cooperative, collaborative and consultative partnership that the faculty have developed with the regional health authorities are together what makes the University of Gezira faculty of medicine experience unique and can be considered as a beacon for its approach to medical education not only for underdeveloped Africa, but also for other third-world nations and more affluent developed countries as well." (14).

An international expert group - the Sub-Saharan African Medical Schools' Studies (sponsored by the Bill and Melinda Gates Foundation and organized by George Washington University)_-commented during their most recent visit to the faculty in February 2010: "The socially accountable medical practice has been ingrained into the University of Gezira faculty of medicine students' as well as graduates' thinking and analytic processes, so much so that the students as well as graduates see even different specializations as means to address their communities' specific health needs. [The faculty] also has a strong history of leadership throughout the years that provides institutional memory and cohesiveness. The processes and methods of the seamless work between the school and the government to achieve a common goal is an innovation to be replicated elsewhere." (15).

\section{Discussion}

Even before WHO defined social accountability of medical schools in 1995 (1), the University of Gezira has been active as a community-engaged leader in the Eastern Mediterranean Region and in sub-Saharan Africa in aligning its education, research, services and resources with the priority needs of the region. It has been mentioned in the literature that medical schools should expand their clinical services to the community, provide community-based residency placements and offer continuing medical education in rural areas. The philosophy and curriculum of the University of Gezira medical school is based on such a concept. Nevertheless it has been noted in the literature that placing students in the community it is not itself sufficient to ensure social accountability (16).

The University programme ensures in its mandate a commitment to community-centred learning, together with funding that is targeted on education. Staff expressed their dissatisfaction, however, with the lack of funding for research. This agrees with another author who commented about the health, illness and the community course at University of Toronto in Canada: "what is needed now is a more comprehensive acceptance by the faculty to ensure in its mandate the commitment to community-centred learning, together with well-targeted funding for education and research initiatives" (17).

Like other schools in Sudan, the University of Gezira medical faculty is accredited by the Sudan Medical Council. The domain of social accountability, however, has not been addressed in-depth by the majority of the medical schools in Sudan. This highlights a clear need for a common, rigorous evaluation tool to measure the impact of socially accountable medical education programmes on health outcomes and on the deployment and retention of doctors in underserved areas. While it will be difficult to demonstrate a linear relationship between socially accountable education interventions and health outcomes, medical schools that are community engaged and striving to be socially accountable are committed to conducting collaborative research and developing a common evaluation framework to strengthen the evidence base on how to train doctors to meet health needs in underserved area (16).

From a methodological point of view, this study has shown that the WHO social accountability grid (1) can be used to assess medical schools. However, more studies from different medical schools are needed to test its validity. Combining this approach to the assessment of medical schools with the conceptual model addresses the need for a more collaborative role of the medical institutes with the health system planners to ensure that their medical professionals are put to their best use. Our review highlights the need to find well-defined social accountability indicators. Application of an appropriate evaluation framework is also needed in order to make studies in this area more comparable between medical schools worldwide.

University of Gezira is now part of the THEnet initiative, which aims to transform the role of medical schools to become active players in the development of healthier, more equitable societies (5). Further studies are needed to evaluate the Gezira faculty's interventions using appropriate methods such as THEnet evaluation framework which was approved by WHO.

\section{Conclusions}

Based on our review and the comments of outside assessors we can conclude that the University of Gezira faculty of medicine is socially responsible and responsive and is progressing successfully towards being fully socially accountable. This should be supported and documented by future studies and research, using appropriate methods such as THEnet evaluation framework 


\section{Acknowledgements}

The authors would like to thank Professor A.J. Neusy for his valuable comments on this article. We extend our thanks to the Gezira family medicine director and his staff, for their great help in providing documents, and to the faculty's administrative staff for providing faculty and student reports.

Funding: None.

Competing interests: None declared.

\section{References}

1. Boelen C, Heck J. Defining and measuring the social accountability of medical schools. Geneva, Switzerland: Division of Development of Human Resources for Health, World Health Organization; 1995.

2. Boelen C. Improving the impact on health: the social accountability approach. Texto Contexto Enferm, Florianópolis. 2015 Jul-Sep;24(3):615-6.

3. Global Consensus for Social Accountability of Medical Schools [Internet] (http://healthsocialaccountability.sites.olt.ubc.ca/ files/2011/06/11-06-07-GCSA-English-pdf-style.pdfhttp:// healthsocialaccountability.sites.olt.ubc.ca/files/2011/06/1106-07-GCSA-English-pdf-style.pdf, accessed 1 April 2016).

4. THEnet's evaluation framework for socially accountable health professional education. Version 1.0. Monograph I. Brussels: The Training for Health Equity Network; 2011 (http://thenetcommunity.org/wp-content/uploads/2013/05/The-Monograph.pdf, accessed 1 April 2016).

5. Magzoub MEMA. Schmidt HG. A taxonomy of community based education, studies in community based education. Acad Med. 2000;75:699-707.

6. Boelen BW. Social accountability and accreditation: a new frontier for educational institutions Med Educ. 2009;43:88794.

7. Second comprehensive programme evaluation report. Gezira, Sudan: Faculty of Medicine, University of Gezira; 2000.

8. Woollard B. Building a different future together, global consensus for social accountability of medical schools. Keynote address to The Network: Towards Unity for Health 2011 Conference, Graz, Austria, 19 September 2011. www.healthsocialaccountability.org Global Consensus for Social Accountability of Medical Schools

9. Hamad B. Establishing community oriented medical schools key issues and steps in early planning. Med Educ. 1999;33:3829. PMID:10336775
10. Mohamed KG, Hunskaar S, Abdelrahman SH, MalikEM. Scaling up family medicine training in Gezira, Sudan: a 2-year in-service master programme using modern information and communication technology: a survey study. Hum Resour Health. 201401 21;12:3. 10.1186/1478-4491-12-3 PMID:24443978

11. Transformative scale up of health professional education. An effort to increase the numbers of health professionals and to strengthen their impact on population health. Geneva: World Health Organization; 2011 (WHO/HSS/HRH/HEP/2011.01) (http://whqlibdoc.who.int/hq/2011/WHO_HSS_HRH_ HEP2011.01_eng.pdf, accessed 1 April 2016).

12. Sanousi $\mathrm{S}$, Babiker $\mathrm{A}$. The emergence of measles among basic school children in Wad Medani. Is a second dose of measles vaccine needed? Sudanese J Paediatr. 2003;6:80-9.

13. Pálsdóttir B, Neusy A-J, Reed G. Building the evidence base: networking innovative socially accountable medical education programs. Education for Health. 2008;21(2):1-6 (http:// www.nosm.ca/uploadedFiles/About_Us/Governance/Academic_Council/THEnet\%20JA\%20EfH\%20Sep08.pdf, accessed 1 April 2016).

14. Elhadi M, Elbadawi A, Abdelrahman S, Mohammed I, Bozicevic I, Hassan EA, et al. Integrated bio-behavioral HIV surveillance surveys among female sex workers in Sudan, 2011-2012. Sex Transm Infect. 2013;89:iii17-22. PMID:23996450

15. The Sub-Saharan African Medical School Study: data, observation, and opportunity. Washington (DC): George Washington University Medical School/University of Pretoria/Bill and Melinda Gates Foundation (www.mepinetwork.org, accessed 1 April 2016).

16. Burdick WP, Morahan PS, Norcini JJ. Capacity building in medical education and health outcomes in developing countries: the missing link. Educ Health (Abingdon). 2007 Nov;20(3):65.

17. Hennen B. Demonstrating social accountability in medical education. CMAJ. 1997 Feb 1;156(3):365-7. PMID:9033418 